\title{
Social Frailty Leads to the Development of Physical Frailty among Physically Non-Frail Adults: A Four-Year Follow-Up Longitudinal Cohort Study
}

\author{
Hyuma Makizako ${ }^{1,2, *}$, Hiroyuki Shimada ${ }^{2}$, Takehiko Doi ${ }^{2}$, Kota Tsutsumimoto ${ }^{2}$, Ryo Hotta ${ }^{2}$, \\ Sho Nakakubo ${ }^{2}$, Keitaro Makino ${ }^{2}$ and Sangyoon Lee ${ }^{2}$ \\ 1 Department of Physical Therapy, School of Health Sciences, Faculty of Medicine, Kagoshima University, \\ Kagoshima 890-8544, Japan \\ 2 Department of Preventive Gerontology, Center for Gerontology and Social Science, National Center for \\ Geriatrics and Gerontology, Aichi 474-8511, Japan; shimada@ncgg.go.jp (H.S.); take-d@ncgg.go.jp (T.D.); \\ k-tsutsu@ncgg.go.jp (K.T.); ryo-h@ncgg.go.jp (R.H.); sho-n@ncgg.go.jp (S.N.); kmakino@ncgg.go.jp (K.M.); \\ sylee@ncgg.go.jp (S.L.) \\ * Correspondence: makizako@health.nop.kagoshima-u.ac.jp; Tel.: +81-99-275-5111
}

Received: 8 February 2018; Accepted: 10 March 2018; Published: 10 March 2018

\begin{abstract}
Social frailty domains may play an important role in preventing physical decline and disability. The aim of this study is to examine the impact of social frailty as a risk factor for the future development of physical frailty among community-dwelling older adults who are not yet physically frail. A total of 1226 physically non-frail older adults were analyzed to provide a baseline. Participants completed a longitudinal assessment of their physical frailty 48 months later. Their baseline social frailty was determined based on their responses to five questions, which identified participants who went out less frequently, rarely visited friends, felt less like helping friends or family, lived alone and did not talk to another person every day. Participants with none of these characteristics were considered not to be socially frail; those with one characteristic were considered socially pre-frail; and those with two or more characteristics were considered socially frail. At the four-year follow-up assessment, 24 participants (2.0\%) had developed physical frailty and $440(35.9 \%)$ had developed physical pre-frailty. The rates of developing physical frailty and pre-frailty were $1.6 \%$ and $34.2 \%$, respectively, in the socially non-frail group; $2.4 \%$ and $38.8 \%$, respectively, in the socially pre-frail group; and $6.8 \%$ and $54.5 \%$, respectively, in the socially frail group. Participants classified as socially frail at the baseline had an increased risk of developing physical frailty, compared with participants who were not socially frail $(\mathrm{OR}=3.93,95 \% \mathrm{CI}=1.02-15.15)$. Participants who were socially frail at the baseline also had an increased risk of developing physical pre-frailty (OR $=2.50,95 \% \mathrm{CI}=1.30-4.80)$. Among independent community-dwelling older adults who are not physically frail, those who are socially frail may be at greater risk of developing physical frailty in the near future. Social frailty may precede (and lead to the development of) physical frailty.
\end{abstract}

Keywords: social frailty; physical frailty; longitudinal cohort study; aged

\section{Introduction}

Frailty is a state of being vulnerable to the poor resolution of homoeostasis after a stressor event. It is a consequence of the cumulative damage done to many physiological systems over a lifetime [1]. Older adults with frailty have an increased risk of adverse health outcomes, such as falling, various disabilities, hospitalization and death [2-4]. Assessments to identify frailty and intervention strategies to reduce and prevent frailty are therefore important topics in an aging society.

The definition of the physical frailty phenotype is well known; many previous studies have examined its impact on adverse health outcomes [5]. Although frailty is recognized as a 
multidimensional construct comprising not only physical, but also psychological and social conditions and symptoms [6,7], the psychological and social domains of frailty have not been sufficiently explored [8,9]. In recent years, some researchers have developed indexes of social frailty $[10,11]$ and social vulnerability $[12,13]$ to assess the impact of social frailty on health outcomes.

Social frailty domains, including social roles, social networks and social activity in older adults, may require higher levels of functioning. A decline in social roles is likely to precede the onset of IADL (intellectual and instrumental activity of daily living) disabilities among community-dwelling independent older adults [14]. Previous studies have demonstrated that low levels of social activity, low participation in social roles and poor social relationships have a negative impact on physical and cognitive function [15-18]. In addition, loneliness and social isolation have a negative impact on health outcomes. [19] Loneliness is associated with a more rapid motor decline in old age [17]. Social frailty domains may play an important role in preventing physical decline and disability $[10,11,20]$. However, it is unclear whether social frailty is caused by a physical frailty phenotype.

Examining the longitudinal relationship between physical and social domains may provide information that could help to develop more effective strategies for preventing the multidimensional construct of frailty. This prospective study has examined the impact of social frailty as a risk factor for the future development of physical frailty among community-dwelling older adults who are not yet physically frail.

\section{Materials and Methods}

\subsection{Participants}

This prospective study has analyzed data drawn from the Obu Health Promotion for the Elderly Study (OSHPE). The OSHPE is a part of a National Center for Geriatrics and Gerontology Study of Geriatric Syndromes (NCGG-SGS), a cohort study whose primary goal was to establish a screening system for geriatric syndromes in the community-dwelling population [21,22].

The present study has analyzed longitudinal data from 1226 community-dwelling older adults $\geq 65$ years (mean age $70.4 \pm 4.1$ years), who participated in both the first and second waves of the OSHPE and who were not physically frail at the time of the first wave assessment. The first wave of the OSHPE was held between August 2011 and February 2012; during this wave, 5104 community-dwelling elderly people participated in a baseline OSHPE assessment. Among participants who took part in the first wave of the OSHPE, 2834 participated in a second wave OSHPE assessment. This four-year follow-up assessment was held between August 2015 and February 2016.

The present longitudinal study looks at participants who had no physical frailty or pre-frailty at the time of the baseline assessment. Participants with a baseline history of stroke, Parkinson's disease or cognitive impairment (e.g., Mini-Mental State Examination (MMSE) score [23] < 18) were excluded (Figure 1). These medical conditions can cause disease-based decline, as opposed to age-related decline, and could thus have reduced the reliability and validity of our frailty assessments. Informed consent was obtained from all participants prior to their inclusion in the study. The Ethics Committee of the National Center for Gerontology and Geriatrics approved the study protocol (Ref No. 923). 


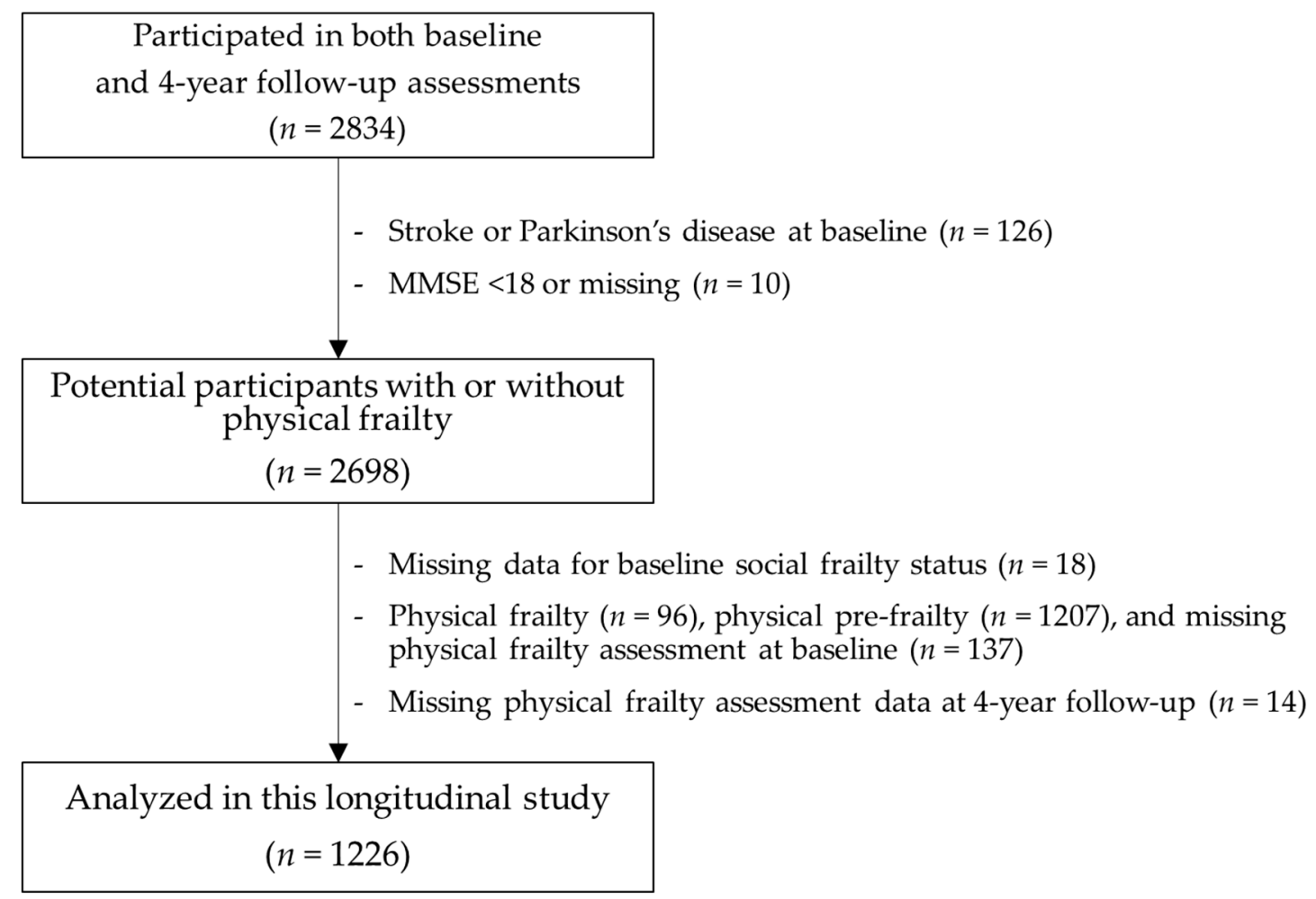

Figure 1. Participant inclusion criteria flow diagram. MMSE: Mini-Mental State Examination.

\subsection{Physical Frailty}

The status of physical frailty is based on the following five conditions: slowness, weakness, exhaustion, low levels of activity and weight loss [2]. Slowness is established using a predetermined cut-off $(<1.0 \mathrm{~m} / \mathrm{s})$ for comfortable walking speed [24]. Weakness is defined using maximum grip strength and gender-specific cut-offs ( $<26 \mathrm{~kg}$ for men and $<18 \mathrm{~kg}$ for women) [25]. Exhaustion is present if the participant answers "yes" to the following question from the Kihon Checklist, a self-reported comprehensive health checklist developed by the Japanese Ministry of Health, Labor and Welfare [26]: "In the last two weeks, have you felt tired for no reason?" We evaluated the participants' levels of physical activity by asking the following questions: (1) "Do you engage in moderate levels of physical exercise or sports aimed at health?" and (2) "Do you engage in low levels of physical exercise aimed at health?" Participants who answered "no" to both questions were classified as having low levels of activity [24]. Participants were assessed as having weight loss if they answered "yes" to the question, "Have you lost $2 \mathrm{~kg}$ or more in the past six months?" [26]. Participants with none of these characteristics were not physically frail; those with one or two characteristics were considered physically pre-frail; and those with three or more characteristics were considered physically frail [27]. In this study, we examined physical frailty status at the baseline and at four-year follow-up assessments. Participants who were not physically frail at the baseline were assessed during the four-year follow-up period to see whether they had developed any physical frailty or pre-frailty.

\subsection{Social Frailty}

To assess and determine the participants' social frailty, we prepared a questionnaire with seven questions about daily social activities, social roles and social relationships [11]. Five of the seven items in the self-reported questionnaire were significantly associated with disability-related incidents; these were going out less frequently than last year (yes), visiting friends sometimes (no), feeling like helping friends or family (no), living alone (yes) and talking with someone every day (no). Two items (getting bored often and having friends to talk to on the telephone) were not significantly associated 
with disability-related incidents [11]. The five questions above (used to define social frailty) had a significant association with disability-related incidents in a previous study. Participants with none of these conditions were not frail; those with one condition were considered pre-frail; and those with two or more components were considered frail [11]. The baseline social frailty levels of participants were grouped into the following three categories: not socially frail, pre-fail and frail.

\subsection{Covariates}

Using face-to-face interviews, we examined the participants' characteristics and medical histories. Each person's body mass index (BMI) and physical performance, including grip strength and walking speed at baseline, were examined as covariates. The grip strength of each participant's dominant hand was measured in kilograms, using a Smedley-type handheld dynamometer (GRIP-D; Takei Ltd., Niigata, Japan) [28]. Walking speed was measured in seconds, using a stopwatch. Participants were asked to walk on a flat, straight surface at a comfortable walking speed. Two markers indicated the start and end of a 2.4- $\mathrm{m}$ path. Participants walked $2 \mathrm{~m}$ before passing the start, so as to be walking at a comfortable pace by the time they reached the timed section of the path [28].

\subsection{Statistical Analysis}

This study used Mantel-Haenszel tests to define the proportion trend and a one-way analysis of variance (ANOVA) for continuous measures to test differences in the baseline characteristics of different groups, based on baseline social frailty status. Incidents related to physical frailty and pre-frailty were calculated for each group during the four-year follow-up assessment. Participants were classified as not socially frail, pre-frail and frail, in accordance with their baseline social frailty status.

The association between baseline social frailty and the development of physical frailty or pre-frailty over four years was examined using multivariate logistic regression analyses. The first model (Model 1) in the multivariate logistic regression analysis was adjusted for age and gender. Model 2 included age, gender, BMI, MMSE, the number of prescribed medications, hypertension, heart disease, diabetes mellitus, osteoporosis and physical frailty status as covariates. The adjusted odds ratios (ORs) for incidents related to physical frailty and/or pre-frailty were estimated with 95\% confidence intervals (95\% CIs). All analyses were conducted using IBM SPSS Statistics 24.0 (IBM Japan, Tokyo, Japan). The level of statistical significance was set at $p<0.05$.

\section{Results}

\subsection{Subsection Characteristics of Participants}

The baseline characteristics of the participants and the differences in social frailty between the groups are described in Table 1 . Of the 1226 participants who were not physically frail, $250(20.4 \%)$ were considered socially pre-frail and $44(3.6 \%)$ were considered socially frail at the baseline assessment. There were no differences in the baseline characteristics, such as age, gender, medical history, prescribed medications, BMI and grip strength, of groups divided by social frailty status. However, there was a difference in walking speed, with the social frailty group walking at a slower speed $(p=0.009)$.

Table 1. Baseline characteristics of the participants, mean \pm SD or $\%$.

\begin{tabular}{lcccc}
\hline \multicolumn{1}{c}{ Variable } & $\begin{array}{c}\text { Social Non-Frailty } \\
(\boldsymbol{n = 9 3 2 )}\end{array}$ & $\begin{array}{c}\text { Social Pre-Frailty } \\
(\boldsymbol{n}=\mathbf{2 5 0})\end{array}$ & $\begin{array}{c}\text { Social Frailty } \\
(\boldsymbol{n}=\mathbf{4 4})\end{array}$ & $\boldsymbol{p}^{\text {a }}$ \\
\hline Age, mean \pm SD (years) & $70.4 \pm 4.1$ & $70.4 \pm 4.0$ & $71.3 \pm 5.8$ & 0.340 \\
Women, $n(\%)$ & $482(51.7 \%)$ & $126(50.4 \%)$ & $25(56.8 \%)$ & 0.871 \\
Medical history, $n(\%)$ & & & & \\
$\quad$ Hypertension & $353(37.9 \%)$ & $99(39.6 \%)$ & $18(40.9 \%)$ & 0.541 \\
Heart disease & $138(14.8 \%)$ & $39(15.6 \%)$ & $4(9.1 \%)$ & 0.654 \\
$\quad$ Diabetes mellitus & $86(9.2 \%)$ & $24(9.6 \%)$ & $4(9.1 \%)$ & 0.914 \\
$\quad$ Osteoporosis $b$ & $91(9.8 \%)$ & $32(12.8 \%)$ & $2(4.5 \%)$ & 0.785 \\
Prescribed medications, mean \pm SD (number) & $1.5 \pm 1.7$ & $1.7 \pm 2.0$ & $1.8 \pm 1.5$ & 0.191 \\
\hline
\end{tabular}


Table 1. Cont.

\begin{tabular}{lcccc}
\hline \multicolumn{1}{c}{ Variable } & $\begin{array}{c}\text { Social Non-Frailty } \\
(\boldsymbol{n}=\mathbf{9 3 2})\end{array}$ & $\begin{array}{c}\text { Social Pre-Frailty } \\
(\boldsymbol{n}=\mathbf{2 5 0})\end{array}$ & $\begin{array}{c}\text { Social Frailty } \\
(\boldsymbol{n}=\mathbf{4 4 )}\end{array}$ & $\boldsymbol{p}^{\text {a }}$ \\
\hline BMI, mean $\pm \mathrm{SD}\left(\mathrm{kg} / \mathrm{m}^{2}\right)$ & $23.3 \pm 3.0$ & $23.3 \pm 3.1$ & $23.3 \pm 3.0$ & 0.959 \\
Physical performance & & & & \\
$\quad$ Grip strength, mean $\pm \mathrm{SD}(\mathrm{kg})$ & $29.0 \pm 7.4$ & $28.5 \pm 7.5$ & $28.1 \pm 7.4$ & 0.567 \\
$\quad$ Walking speed, mean $\pm \mathrm{SD}(\mathrm{m} / \mathrm{s})$ & $1.32 \pm 0.17$ & $1.30 \pm 0.17$ & $1.25 \pm 0.16$ & 0.009 \\
\hline
\end{tabular}

$\mathrm{SD}$, standard deviation; BMI, body mass index; ${ }^{\text {a }}$ Mantel-Haenszel test for proportion trends and one-way analysis of variance for continuous measures; ${ }^{b}$ missing values for osteoporosis $(n=1)$.

\subsection{Associations between Social Frailty and the Development of Physical Frailty}

During the four-year follow-up assessment, 24 participants $(2.0 \%)$ developed physical frailty and $440(35.9 \%)$ developed physical pre-frailty. The rates of developing physical frailty and pre-frailty were $1.6 \%$ and $34.2 \%$ in the non-frail group, $2.4 \%$ and $38.8 \%$ in the socially pre-frail group and $6.8 \%$ and $54.5 \%$ in the socially frail group, respectively.

The results of the multivariate logistic regression analyses are represented in Tables 2 and 3. The multivariate logistic regression analyses indicated that baseline social frailty significantly increased the risk of physical frailty-related incidents (OR 4.47, 95\% CI 1.25-16.06), as well as physical pre-frailty (OR 2.84, 95\% CI 1.53-5.29) in crude models. However, baseline social pre-frailty was not significantly associated with an increased risk of physical frailty or with pre-frailty-related incidents. In the adjusted model (Model 2), which included potential covariates, participants who were classified as socially frail at the baseline had an increased risk of developing physical frailty, compared with participants who were not socially frail (OR 3.93, 95\% CI 1.02-15.15). Those with baseline social frailty were also at greater risk of developing physical pre-frailty (OR 2.50, 95\% CI 1.30-4.80).

Table 2. Odds ratios for the development of physical frailty after four years, with reference to baseline social frailty status among older adults without physical frailty.

\begin{tabular}{|c|c|c|c|c|c|c|}
\hline \multirow{3}{*}{ Baseline Status of Social Frailty } & \multicolumn{6}{|c|}{ Dependent Value: Incidence of Physical Frailty } \\
\hline & \multicolumn{2}{|c|}{ Crude } & \multicolumn{2}{|c|}{ Model 1} & \multicolumn{2}{|c|}{ Model 2} \\
\hline & OR & $95 \% \mathrm{CI}$ & OR & $95 \%$ CI & OR & $95 \%$ CI \\
\hline Not socially frail & 1 & [Reference] & 1 & [Reference] & 1 & [Reference] \\
\hline Socially pre-frail & 1.50 & $0.58-3.92$ & 1.49 & $0.57-3.90$ & 1.22 & $0.45-3.25$ \\
\hline Socially frail & $4.47^{*}$ & $1.25-16.06$ & 3.98 * & $1.09-14.59$ & 3.93 * & $1.02-15.15$ \\
\hline
\end{tabular}

Note: OR, odds ratio; $\mathrm{CI}$, confidence interval; the bold typeface indicates statistical significance; ${ }^{*} p<0.05$; Model 1: adjusted for age and gender; Model 2: adjusted for age, gender, BMI, number of prescribed medications, hypertension, heart disease, diabetes mellitus, osteoporosis, grip strength (baseline) and walking speed (baseline).

Table 3. Odds ratios for the development of physical frailty or pre-frailty after four years, with reference to baseline social frailty status among older adults without physical frailty.

\begin{tabular}{|c|c|c|c|c|c|c|}
\hline \multirow{3}{*}{ Baseline Status of Social Frailty } & \multicolumn{6}{|c|}{ Dependent Value: Incidents Related to Physical Frailty or Pre-Frailty } \\
\hline & \multicolumn{2}{|l|}{ Crude } & \multicolumn{2}{|c|}{ Model 1} & \multicolumn{2}{|c|}{ Model 2} \\
\hline & OR & $95 \%$ CI & OR & $95 \%$ CI & OR & $95 \%$ CI \\
\hline Not socially frail & 1 & [Reference] & 1 & [Reference] & 1 & [Reference] \\
\hline Socially pre-frail & 1.26 & $0.94-1.67$ & 1.27 & $0.95-1.69$ & 1.17 & $0.87-1.58$ \\
\hline Socially frail & $2.84 * *$ & $1.53-5.29$ & $2.75 * *$ & $1.46-5.19$ & $2.50 * *$ & $1.30-4.80$ \\
\hline
\end{tabular}

Note: OR, odds ratio; CI, confidence interval; the bold typeface indicates statistical significance; ${ }^{* *} p<0.01$; Model 1: adjusted for age and gender; Model 2: adjusted for age, gender, BMI, number of prescribed medications, hypertension, heart disease, diabetes mellitus, osteoporosis, grip strength (baseline) and walking speed (baseline).

\section{Discussion}

The present prospective study has revealed that social frailty can lead to physical frailty in a relatively short period of time among adults who are not physically frail. Among community-dwelling older adults who are not physically frail, those with baseline social frailty have approximately 
four times the risk of experiencing an incident related to physical frailty as those who are not socially frail, even after controlling for several potential covariates.

Some recent studies have focused on including or developing social domains to assess frailty $[4,10,11,29,30]$. This study identified the social frailty status of participants using five simple questions: participants with two or more conditions were considered socially frail. Although it may be useful to include other items in the social domain, such as economic status [31] and lifetime occupation [32], this very simple index has been shown to predict an increased risk of disability-related incidents [11]. These simple questions are thus a very useful tool for assessing social frailty.

On the other hand, physical frailty may have a greater impact than social frailty on the incidence of disability. In fact, physical frailty is associated with a greater risk of disability than social frailty in our cohort database $[11,33]$. If social frailty is one of a range of important factors that lead patients who are not frail to develop physical frailty, it is essential to assess social frailty to understand the future risk of poor health outcomes. This prospective study shows that participants with baseline social frailty are approximately four-times more likely to have an incident related to physical frailty in four years than participants who are not socially frail. Although both socially frail and non-frail groups had relatively fast walking speeds ( $>1.25 \mathrm{~m} / \mathrm{s})$, participants with social frailty had slower baseline walking speeds than those without. On the other hand, there was no difference in grip strength. Age-related changes in mobility may be related to increasing social frailty. Older adults who are socially frail, even if they are not physically frail, may be potential targets for disability prevention.

Social aspects of the lives of older adults, including social connectedness, social relations, social engagement and the social environment may impact the extent to which physical functions decline and physical inactivity increases [34-37]. Our previous cross-sectional analysis revealed that older adults with social frailty had lower physical function than those without [20]. Although these social factors may play a role in maintaining good health, including physical functions, few studies have used the concept of frailty to explore the longitudinal relationships between the social and physical domains. The current study has an important clinical message: social frailty leads to the development of physical frailty among adults who are not physically frail. Assessing social frailty and implementing intervention strategies to avoid social frailty may be useful for preventing physical frailty and disability-related incidents.

The current study has focused on the relationship between baseline social frailty and incidents caused by physical frailty. Older adults' social domains may have a positive impact on their cognitive function. Previous studies have indicated that poor social relationships, low levels of social activity and low social engagement are associated, not only with cognitive decline [38,39], but also with an increased risk of dementia [40-42]. As several issues in each domain, including the definition of frailty, need to be further explored, future studies should analyze the relationships between the various domains, including cognitive impairment.

One essential message is that social frailty is reversible [43]. Interactive and social activities, such as having conversations and going outdoors, increase stimulation of the brain [44,45]. Participating in a resident-centered community intervention program called a 'community salon' may also be useful for preventing functional disabilities [46]. Future research should examine whether reducing social frailty by increasing social activity, social engagement and social relationships can help to prevent physical and cognitive frailty.

This study has several limitations. It has not examined adverse relationships or the longitudinal association between baseline physical frailty and future social frailty. Some older adults can expand their life-space through increased social activity, even when they suffer from physical frailty. Interactive associations between the various domains of frailty are needed to develop effective prevention strategies in the community. In addition, this study has not assessed the participants' medical histories or hospital admissions during the follow-up period. Illness and hospitalization may accelerate both the physical and social aspects of age-related functional decline. 


\section{Conclusions}

Among independent community-dwelling older adults who are not physically frail, those who are socially frail may be at greater risk of developing physical frailty in the near future. Social frailty may precede (and lead to the development of) physical frailty.

Acknowledgments: The authors would like to thank the Obu City Office for helping to recruit participants. This study was supported by the Japanese Ministry of Health, Labor and Welfare (Project for optimizing long-term care) (Grant Number B-3); and the National Center for Geriatrics and Gerontology (Research Funding for Longevity Sciences) (Grant Number 26-33).

Author Contributions: Hyuma Makizako was responsible for the study concept and design, subject recruitment, the analysis and interpretation of data and writing the manuscript. Hiroyuki Shimada contributed to the study concept and design, subject recruitment, the interpretation of data and writing the manuscript. Takehiko Doi and Kota Tsutsumimoto were instrumental in recruiting subjects, acquiring data and preparing the manuscript. Ryo Hotta, Sho Nakakubo, Keitaro Makino and Sngyoon Lee helped to interpret the data and prepare the manuscript. All of the authors were involved in designing the study; all contributed to and approved the final manuscript.

Conflicts of Interest: The authors declare no conflicts of interest.

\section{References}

1. Clegg, A.; Young, J.; Iliffe, S.; Rikkert, M.O.; Rockwood, K. Frailty in elderly people. Lancet 2013, 381, 752-762. [CrossRef]

2. Fried, L.P.; Tangen, C.M.; Walston, J.; Newman, A.B.; Hirsch, C.; Gottdiener, J.; Seeman, T.; Tracy, R.; Kop, W.J.; Burke, G.; et al. Frailty in older adults: Evidence for a phenotype. J. Gerontol. A Biol. Sci. Med. Sci. 2001, 56, M146-M157. [CrossRef] [PubMed]

3. Tom, S.E.; Adachi, J.D.; Anderson, F.A., Jr.; Boonen, S.; Chapurlat, R.D.; Compston, J.E.; Cooper, C.; Gehlbach, S.H.; Greenspan, S.L.; Hooven, F.H.; et al. Frailty and fracture, disability, and falls: A multiple country study from the global longitudinal study of osteoporosis in women. J. Am. Geriatr. Soc. 2013, 61, 327-334. [CrossRef] [PubMed]

4. Garre-Olmo, J.; Calvo-Perxas, L.; Lopez-Pousa, S.; de Gracia Blanco, M.; Vilalta-Franch, J. Prevalence of frailty phenotypes and risk of mortality in a community-dwelling elderly cohort. Age Ageing 2013, 42, 46-51. [CrossRef] [PubMed]

5. Vermeiren, S.; Vella-Azzopardi, R.; Beckwee, D.; Habbig, A.K.; Scafoglieri, A.; Jansen, B.; Bautmans, I. Gerontopole Brussels Study Group. Frailty and the prediction of negative health outcomes: A meta-analysis. J. Am. Med. Dir. Assoc. 2016, 17, 1163e1-1163e17. [CrossRef] [PubMed]

6. Rockwood, K. What would make a definition of frailty successful? Age Ageing 2005, 34, 432-434. [CrossRef] [PubMed]

7. Gobbens, R.J.; Luijkx, K.G.; Wijnen-Sponselee, M.T.; Schols, J.M. Toward a conceptual definition of frail community dwelling older people. Nurs. Outlook 2010, 58, 76-86. [CrossRef] [PubMed]

8. Hogan, D.B.; MacKnight, C.; Bergman, H. Steering Committee, Canadian Initiative on Frailty and Aging. Aging: Models, definitions, and criteria of frailty. Aging Clin. Exp. Res. 2003, 15 (Suppl. 3), 1-29. [PubMed]

9. Levers, M.J.; Estabrooks, C.A.; Ross Kerr, J.C. Factors contributing to frailty: Literature review. J. Adv. Nurs. 2006, 56, 282-291. [CrossRef] [PubMed]

10. Teo, N.; Gao, Q.; Nyunt, M.S.Z.; Wee, S.L.; Ng, T.P. Social frailty and functional disability: Findings from the Singapore Longitudinal Ageing Studies. J. Am. Med. Dir. Assoc. 2017, 18, 637e13-637e19. [CrossRef] [PubMed]

11. Makizako, H.; Shimada, H.; Tsutsumimoto, K.; Lee, S.; Doi, T.; Nakakubo, S.; Hotta, R.; Suzuki, T. Social frailty in community-dwelling older adults as a risk factor for disability. J. Am. Med. Dir. Assoc. 2015, 16, 1003.e7-1003.e11. [CrossRef] [PubMed]

12. Andrew, M.K.; Mitnitski, A.B.; Rockwood, K. Social vulnerability, frailty and mortality in elderly people. PLoS ONE 2008, 3, e2232. [CrossRef] [PubMed]

13. Andrew, M.K. Frailty and social vulnerability. Interdiscip. Top. Gerontol. Geriatr. 2015, 41, 186-195. [PubMed] 
14. Fujiwara, Y.; Shinkai, S.; Kumagai, S.; Amano, H.; Yoshida, Y.; Yoshida, H.; Kim, H.; Suzuki, T.; Ishizaki, T.; Haga, H.; et al. Longitudinal changes in higher-level functional capacity of an older population living in a Japanese urban community. Arch. Gerontol. Geriatr. 2003, 36, 141-153. [CrossRef]

15. Kuiper, J.S.; Oude Voshaar, R.C.; Zuidema, S.U.; Stolk, R.P.; Zuidersma, M.; Smidt, N. The relationship between social functioning and subjective memory complaints in older persons: A population-based longitudinal cohort study. Int. J. Geriatr. Psychiatry 2017, 32, 1059-1071. [CrossRef] [PubMed]

16. Buchman, A.S.; Boyle, P.A.; Wilson, R.S.; Fleischman, D.A.; Leurgans, S.; Bennett, D.A. Association between late-life social activity and motor decline in older adults. Arch. Intern. Med. 2009, 169, 1139-1146. [CrossRef] [PubMed]

17. Buchman, A.S.; Boyle, P.A.; Wilson, R.S.; James, B.D.; Leurgans, S.E.; Arnold, S.E.; Bennett, D.A. Loneliness and the rate of motor decline in old age: The Rush Memory and Aging Project, a community-based cohort study. BMC Geriatr. 2010, 10, 77. [CrossRef] [PubMed]

18. Zunzunegui, M.V.; Alvarado, B.E.; Del Ser, T.; Otero, A. Social networks, social integration, and social engagement determine cognitive decline in community-dwelling Spanish older adults. J. Gerontol. B Psychol. Sci. Soc. Sci. 2003, 58, S93-S100. [CrossRef] [PubMed]

19. Tomaka, J.; Thompson, S.; Palacios, R. The relation of social isolation, loneliness, and social support to disease outcomes among the elderly. J. Aging Health 2006, 18, 359-384. [CrossRef] [PubMed]

20. Tsutsumimoto, K.; Doi, T.; Makizako, H.; Hotta, R.; Nakakubo, S.; Makino, K.; Suzuki, T.; Shimada, H. Association of social frailty with both cognitive and physical deficits among older people. J. Am. Med. Dir. Assoc. 2017, 18, 603-607. [CrossRef] [PubMed]

21. Shimada, H.; Tsutsumimoto, K.; Lee, S.; Doi, T.; Makizako, H.; Lee, S.; Harada, K.; Hotta, R.; Bae, S.; Nakakubo, S.; et al. Driving continuity in cognitively impaired older drivers. Geriatr. Gerontol. Int. 2016, 16, 508-514. [CrossRef] [PubMed]

22. Shimada, H.; Makizako, H.; Lee, S.; Doi, T.; Lee, S.; Tsutsumimoto, K.; Harada, K.; Hotta, R.; Bae, S.; Nakakubo, S.; et al. Impact of Cognitive Frailty on Daily Activities in Older Persons. J. Nutr. Health Aging 2016, 20, 729-735. [CrossRef] [PubMed]

23. Folstein, M.F.; Folstein, S.E.; McHugh, P.R. "Mini-mental state". A practical method for grading the cognitive state of patients for the clinician. J. Psychiatr. Res. 1975, 12, 189-198. [CrossRef]

24. Shimada, H.; Makizako, H.; Doi, T.; Yoshida, D.; Tsutsumimoto, K.; Anan, Y.; Uemura, K.; Ito, T.; Lee, S.; Park, H.; et al. Combined prevalence of frailty and mild cognitive impairment in a population of elderly Japanese people. J. Am. Med. Dir. Assoc. 2013, 14, 518-524. [CrossRef] [PubMed]

25. Chen, L.K.; Liu, L.K.; Woo, J.; Assantachai, P.; Auyeung, T.W.; Bahyah, K.S.; Chou, M.Y.; Chen, L.Y.; Hsu, P.S.; Krairit, O.; et al. Sarcopenia in Asia: Consensus report of the Asian Working Group for Sarcopenia. J. Am. Med. Dir. Assoc. 2014, 15, 95-101. [CrossRef] [PubMed]

26. Fukutomi, E.; Okumiya, K.; Wada, T.; Sakamoto, R.; Ishimoto, Y.; Kimura, Y.; Chen, W.L.; Imai, H.; Kasahara, Y.; Fujisawa, M.; et al. Relationships between each category of 25-item frailty risk assessment (Kihon Checklist) and newly certified older adults under Long-Term Care Insurance: A 24-month follow-up study in a rural community in Japan. Geriatr. Gerontol. Int. 2015, 15, 864-871. [CrossRef] [PubMed]

27. Shimada, H.; Makizako, H.; Doi, T.; Tsutsumimoto, K.; Suzuki, T. Incidence of disability in frail older persons with or without slow walking speed. J. Am. Med. Dir. Assoc. 2015, 16, 690-696. [CrossRef] [PubMed]

28. Makizako, H.; Shimada, H.; Doi, T.; Tsutsumimoto, K.; Lee, S.; Lee, S.C.; Harada, K.; Hotta, R.; Nakakubo, S.; Bae, S.; et al. Age-dependent changes in physical performance and body composition in community-dwelling Japanese older adults. J. Cachexia Sarcopenia Muscle 2017, 8, 607-614. [CrossRef] [PubMed]

29. Gobbens, R.J.; van Assen, M.A.; Luijkx, K.G.; Wijnen-Sponselee, M.T.; Schols, J.M. Determinants of frailty. J. Am. Med. Dir. Assoc. 2010, 11, 356-364. [CrossRef] [PubMed]

30. Bunt, S.; Steverink, N.; Andrew, M.K.; Schans, C.P.V.; Hobbelen, H. Cross-cultural adaptation of the social vulnerability index for use in the Dutch context. Int. J. Environ. Res. Public Health 2017, 14, 1387. [CrossRef] [PubMed]

31. Lang, I.A.; Hubbard, R.E.; Andrew, M.K.; Llewellyn, D.J.; Melzer, D.; Rockwood, K. Neighborhood deprivation, individual socioeconomic status, and frailty in older adults. J. Am. Geriatr. Soc. 2009, 57, 1776-1780. [CrossRef] [PubMed] 
32. Alvarado, B.E.; Zunzunegui, M.V.; Beland, F.; Bamvita, J.M. Life course social and health conditions linked to frailty in Latin American older men and women. J. Gerontol. A Biol. Sci. Med. Sci. 2008, 63, 1399-1406. [CrossRef] [PubMed]

33. Makizako, H.; Shimada, H.; Doi, T.; Tsutsumimoto, K.; Suzuki, T. Impact of physical frailty on disability in community-dwelling older adults: A prospective cohort study. BMJ Open 2015, 5, e008462. [CrossRef] [PubMed]

34. Clarke, C.L.; Sniehotta, F.F.; Vadiveloo, T.; Argo, I.S.; Donnan, P.T.; McMurdo, M.E.T.; Witham, M.D. Factors associated with change in objectively measured physical activity in older people-Data from the physical activity cohort Scotland study. BMC Geriatr. 2017, 17, 180. [CrossRef] [PubMed]

35. Jang, Y.; Park, N.S.; Dominguez, D.D.; Molinari, V. Social engagement in older residents of assisted living facilities. Aging Ment. Health 2014, 18, 642-647. [CrossRef] [PubMed]

36. Van Holle, V.; Van Cauwenberg, J.; De Bourdeaudhuij, I.; Deforche, B.; Van de Weghe, N.; Van Dyck, D. Interactions between neighborhood social environment and walkability to explain Belgian older adults' physical activity and sedentary time. Int. J. Environ. Res. Public Health 2016, 13, E569. [CrossRef] [PubMed]

37. McAuley, E.; Blissmer, B.; Marquez, D.X.; Jerome, G.J.; Kramer, A.F.; Katula, J. Social relations, physical activity, and well-being in older adults. Prev. Med. 2000, 31, 608-617. [CrossRef] [PubMed]

38. Brown, C.L.; Robitaille, A.; Zelinski, E.M.; Dixon, R.A.; Hofer, S.M.; Piccinin, A.M. Cognitive activity mediates the association between social activity and cognitive performance: A longitudinal study. Psychol. Aging 2016, 31, 831-846. [CrossRef] [PubMed]

39. Park, S.; Kwon, E.; Lee, H. Life course trajectories of later-life cognitive functions: Does social engagement in old age matter? Int. J. Environ. Res. Public Health 2017, 14, 393. [CrossRef] [PubMed]

40. Kuiper, J.S.; Zuidersma, M.; Oude Voshaar, R.C.; Zuidema, S.U.; van den Heuvel, E.R.; Stolk, R.P.; Smidt, N. Social relationships and risk of dementia: A systematic review and meta-analysis of longitudinal cohort studies. Ageing Res. Rev. 2015, 22, 39-57. [CrossRef] [PubMed]

41. Saczynski, J.S.; Pfeifer, L.A.; Masaki, K.; Korf, E.S.; Laurin, D.; White, L.; Launer, L.J. The effect of social engagement on incident dementia: The Honolulu-Asia Aging Study. Am. J. Epidemiol. 2006, 163, 433-440. [CrossRef] [PubMed]

42. Marioni, R.E.; Proust-Lima, C.; Amieva, H.; Brayne, C.; Matthews, F.E.; Dartigues, J.F.; Jacqmin-Gadda, H. Social activity, cognitive decline and dementia risk: A 20-year prospective cohort study. BMC Public Health 2015, 15, 1089. [CrossRef] [PubMed]

43. Chen, X.; Mao, G.; Leng, S.X. Frailty syndrome: An overview. Clin. Interv. Aging 2014, 9, 433-441. [PubMed]

44. Makizako, H.; Doi, T.; Shimada, H.; Park, H.; Uemura, K.; Yoshida, D.; Tsutsumimoto, K.; Anan, Y.; Suzuki, T. Relationship between going outdoors daily and activation of the prefrontal cortex during verbal fluency tasks (VFTs) among older adults: A near-infrared spectroscopy study. Arch. Gerontol. Geriatr. 2013, 56, 118-123. [CrossRef] [PubMed]

45. Suda, M.; Takei, Y.; Aoyama, Y.; Narita, K.; Sato, T.; Fukuda, M.; Mikuni, M. Frontopolar activation during face-to-face conversation: An in situ study using near-infrared spectroscopy. Neuropsychologia 2010, 48, 441-447. [CrossRef] [PubMed]

46. Hikichi, H.; Kondo, N.; Kondo, K.; Aida, J.; Takeda, T.; Kawachi, I. Effect of a community intervention programme promoting social interactions on functional disability prevention for older adults: Propensity score matching and instrumental variable analyses, JAGES Taketoyo study. J. Epidemiol. Community Health 2015, 69, 905-910. [CrossRef] [PubMed]

(C) 2018 by the authors. Licensee MDPI, Basel, Switzerland. This article is an open access article distributed under the terms and conditions of the Creative Commons Attribution (CC BY) license (http://creativecommons.org/licenses/by/4.0/). 